\title{
Colibacillosis in commercial chickens in Bangladesh
}

\author{
R. Khaton, M. G. Haider1, P. K. Paul, P. M. Das and M. M. Hossain ${ }^{4 *}$ \\ Department of Pathology, Faculty of Veterinary Science, Bangladesh Agricultural \\ University, Mymensingh-2202, Bangladesh
}

\begin{abstract}
The prevalence of colibacillosis in layer chickens was studied from May to September 2007. Sixty five cloacal swabs from apparently healthy birds and 55 swabs of liver $(n=15)$, lung $(n=15)$ and intestine $(n=25)$ from 30 dead birds were collected in sterile nutrient broth, with histopathological samples. Bacteria were isolated and identified. Tissue samples were studied under light microscope. Escherichia coli (E. coli) was isolated from $83 \%$ of cloacal swabs of apparently healthy chickens and $87 \%$ of samples from dead birds. Affected birds had cloudy thickened air sacs, pericarditis, congestion in the liver, lung and spleen. On histopathological examination focal necrosis in liver and infiltration of heterophils, lymphocytes and macrophages in liver and lung was found. Thickening of pericardium was found due to infiltration of reticulo endothelial (RE) cells. In duodenum, severe infiltration of leukocytes mainly heterophils, lymphocytes and macrophages was found in the sub-mucosa. (Bangl. vet. 2007. Vol. 25, No. 1, 17-24)
\end{abstract}

\section{Introduction}

In Bangladesh 98\% of poultry are kept in rural area as scavengers (BBS, 1987). More than 130 hatcheries produce 3.4 million day-old chicks per week and about 30,000 commercial broiler and layer farms supply 0.26 million tonnes of poultry meat and 5210 million eggs per year (Rahman, 2003a). About 78\% of the country's eggs and $86 \%$ of poultry meat are produced by rural scavenging birds (Alam, 1995). The advancement of poultry industry is facing a problem due to sudden outbreak of bacterial diseases, including colibacillosis, which poses a serious threat in Bangladesh.

Colibacillosis, caused by $E$ coli, is a major disease of commercial poultry all over the world. It causes serious loss specially if there is bad management or stress in broilers such as complicating infections like chronic respiratory disease (CRD) or mycoplasma (Talha et al., 2001). The major species of E. coli are encountered in the lower intestine of warm-blooded animals and birds, where they cause gastroenteritis (Pelczar et al., 1986). With expansion of poultry farming, colibacillosis has become a widespread problem in Bangladesh (Islam et al., 2003; Rahman, 2003b; Hossain et al., 2004). Heavy economic loss occurs in broilers and layers due to morbidity, mortality, reduced production and poor chick quality (Islam et al., 2003; Rahman, 2003b; Rahman et al., 2004; Hossain et al., 2004). Mortality due to colibacillosis in Bangladesh

\footnotetext{
4 Department of Livestock Services, Government of Bangladesh, Dhaka, Bangladesh, PhD Fellow, Department of Pathology, Bangladesh Agricultural University, Mymensingh, Bangladesh.

* Correspondence :- E-mail : mmhossain04@yahoo.com.au
} 
may reach 94\% in severe outbreaks (Biswas et al., 2006; Haider et al., 2003; Roy et al., 2006).

Investigations on colibacillosis in poultry are still scanty in Bangladesh. The disease pattern is variable. This study was undertaken to know the status of colibacillosis in two commercial poultry farms with isolation and identification of causal agents.

\section{Materials and Methods}

Samples

The study was conducted from May to September 2007. Fifteen samples from layers of 68 weeks old chickens of SEVER 579 from the Bangladesh Agricultural University (BAU) Poultry Farm and 50 samples from layers of 75 weeks old chickens of ISA Brown from Krisibid Poultry Farm, Bhaluka, Mymensingh district were collected in nutrient broth. The samples [ 55 swabs from liver $(n=15)$, lung $(n=15)$, and intestine $(n=25)]$ of 30 dead birds were collected in nutrient broth. The samples were carried in ice box for further study. Samples for histopathology were collected in plastic pot containing $10 \%$ neutral buffered formalin.

\section{Sample collection}

Samples were collected using sterile cotton-tipped swabs from the cloaca of healthy chickens. The swabs were inserted into sterilized screw-capped test tubes containing nutrient broth and preserved at $4^{\circ} \mathrm{C}$. After dissecting the dead birds, the liver, lung and intestine were incised with sterile scissors and intestinal faeces were scraped with a sterile scalpel. Samples were collected from the liver, lung and intestine and swabs were handled carefully as above.

\section{Identification of isolated E. coli}

Cloacal and intestinal samples were placed on nutrient agar plate and incubated overnight at $37^{\circ} \mathrm{C}$. After primary culture, a small amount of inoculum was subcultured in nutrient agar and MacConkey agar to observe colony morphology. Colonies with the features of $E$. coli were selected for subculture on selective media such as Eosin Methylene Blue (EMB) agar (Carter, 1986).

Morphological characterization by Gram-stain

Representative Salmonella colonies were characterized microscopically using Gram's stain as described by Freeman (1985).

\section{Carbohydrate fermentation test}

The carbohydrate fermentation test was performed by inoculating $5 \mathrm{ml}$ of nutrient broth culture of the organisms into tubes containing different sugars and incubated for 72 hours at $37^{\circ} \mathrm{C}$. Acid production was indicated by the colour change 
from red to yellow of the medium and gas production was noted by the appearance of gas bubbles in the inverted Durham's tube.

\section{Methyl red test}

After incubation 2-4 drops of methyl red solution were added to the test tube, which was incubated for 5 days. Positive test was indicated by the persistence of red colour, indicating acidity and negative by yellow colour.

Voges-Proskauer (V-P) test

The VP test was performed by adding $0.6 \mathrm{ml}$ of VP reagent- 1 and $0.2 \mathrm{ml}$ of VP reagent- 2 for each $\mathrm{ml}$ of culture. The ingredients were mixed thoroughly and allowed to stand. A pink colour indicated a positive test.

\section{Motility test}

The motility test was performed as described by Carter (1986). A pure culture of the organism was grown in nutrient broth. The motile organisms were identified visually.

Maintenance of stock culture

Organisms from pure culture were inoculated into tubes containing EMB slant and incubated at $37^{\circ} \mathrm{C}$ for 24 hours. After the growth of organisms the tubes were sealed with sterile liquid paraffin (light) and kept at $4^{\circ} \mathrm{C}$ for further studies.

Gross pathology

At necropsy, gross tissue changes were recorded, and representative tissue samples containing lesions were fixed in 10\% neutral buffered formalin for histopathology (Stubbs, 1954).

Histopathology

The formalin-fixed tissues were processed using standard procedures (Luna, 1968).

\section{Photomicrography}

Photomicrography was taken using Olympus PM-C 35 camera on Olympus microscope (Olympus, Japan).

\section{Results and Discussion}

Prevalence of E. coli in cloaca of healthy chickens and dead chickens.

The prevalence of E. coli was $83 \%$ in apparently healthy chickens (Table 1 ). The prevalence of E. coli was $87 \%$ in 15 liver samples, $73 \%$ in 15 lung samples and $96 \%$ in 
25 intestine samples from 30 dead chickens (Table 2). The prevalence was higher in intestine and liver than lung. However, these findings were lower than those of others (Derakhshantar and Ghanbarpour, 2002; El-Sukhon et al., 2002; Haider et al., 2003) possibly due to the age and breeds of the birds and the resistance of commercial chickens due to better management, vaccination and nutrition. E. coli is normally present in the digestive tract of poultry. Stress may enhance the virulence of E. coli, leading to disease (Talha et al., 2001).

Table 1. Prevalence of E. coli from cloacal swabs of apparently healthy layer chickens

\begin{tabular}{l|c|c|c}
\hline Samples/Swabs & $\begin{array}{c}\text { No. of samples } \\
\text { examined }\end{array}$ & $\begin{array}{c}\text { Total number of +ve } \\
\text { isolates }\end{array}$ & $\begin{array}{c}\text { Overall prevalence } \\
(\%)\end{array}$ \\
\hline Cloacal swabs & 65 & 54 & 83 \\
\hline
\end{tabular}

Table 2. Prevalence of E. coli from 30 layer dead chickens

\begin{tabular}{l|c|c|c|c|c}
\hline Samples & $\begin{array}{c}\text { No. of } \\
\text { samples }\end{array}$ & No. +ve & Prevalence (\%) & $\begin{array}{c}\text { Total No. of +ve } \\
\text { isolates }\end{array}$ & $\begin{array}{c}\text { Overall } \\
\text { prevalence (\%) }\end{array}$ \\
\hline Liver & 15 & 13 & $87 \%$ & 48 & $87 \%$ \\
Lung & 15 & 11 & $73 \%$ & & \\
Intestine & 25 & 24 & $96 \%$ & & \\
\hline
\end{tabular}

\section{Colony characters}

Pink colonies on MacConkey agar and greenish colonies with metallic sheen on EMB agar (Fig. 1) after overnight incubation were confirmed as E. coli: these colony characteristics correspond with the findings of others (Ali et al., 1998; Sharada et al., 1999).

\section{Staining characters and motility test}

Gram's stain

Microscopy revealed Gram-negative, pink, short rod-shaped organisms arranged singly or in pairs (Fig. 2).

\section{Motility test}

All the E. coli isolates were motile. The staining characteristics and motility test were similar to the findings of others (Buxton and Fraser, 1977; Thomas, 1988).

\section{Biochemical tests of the identified bacteria}

Sugar fermentation test

All the isolates fermented dextrose, lactose, maltose and mannitol with the production of acid and gas but did not ferment inositol. Acid production was indicated by the change from reddish to yellow and gas production by the accumulation of gas bubbles in the inverted Durham's tube (Table 3). All the isolates 
were methyl red positive and Voges-Proskauer test negative (Table 3). These findings support the findings of Buxton and Fraser (1977); Freeman (1985); Mishra et al. (2002).

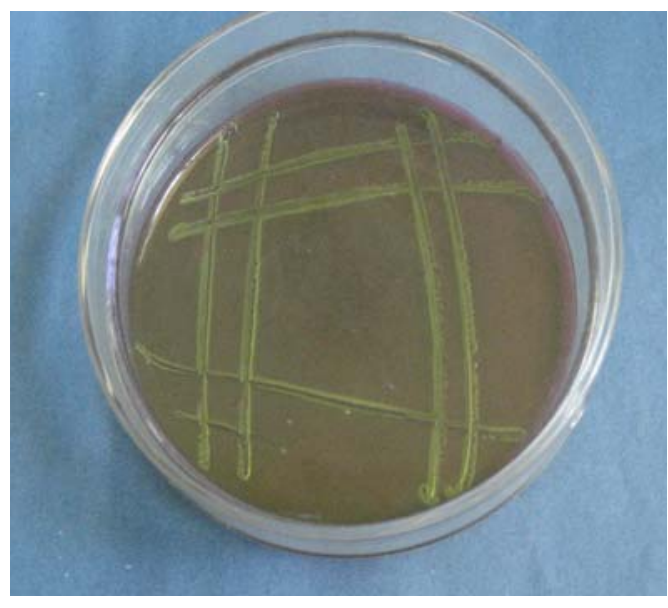

Fig. 1. E. coli colonies showing greenish colour with metallic sheen on Eosin Methylene Blue agar

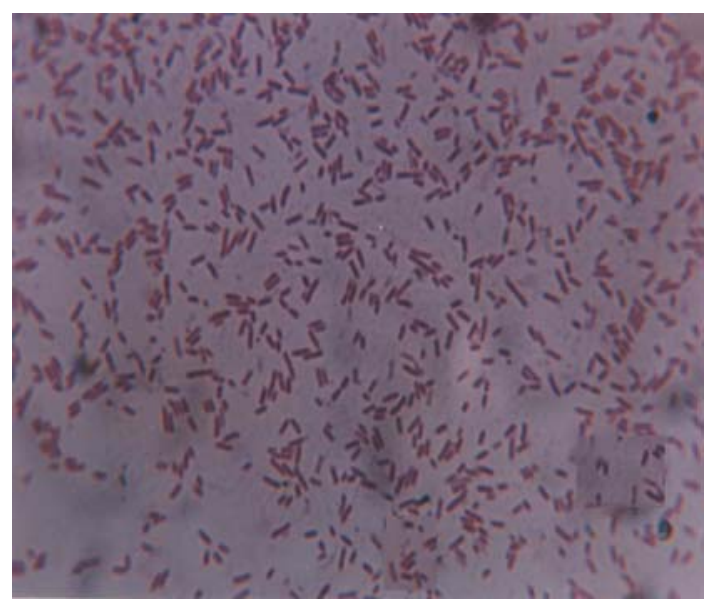

Fig. 2. E. coli in Gram's stain showing Gram negative, pink, short rod-shaped organisms, singly or in pairs ( $x$ 830)

Table 3. Biochemical characteristics of E. coli

\begin{tabular}{|c|c|c|c|c|c|c|c|}
\hline \multirow{2}{*}{$\begin{array}{l}\text { Methyl } \\
\text { red test }\end{array}$} & \multirow{2}{*}{$\begin{array}{c}\text { Voges- } \\
\text { Proskauer test }\end{array}$} & \multirow{2}{*}{$\begin{array}{l}\text { Motility } \\
\text { test }\end{array}$} & \multicolumn{4}{|c|}{ Sugar test } & \multirow{2}{*}{$\begin{array}{l}\text { Bacteria } \\
\text { isolated }\end{array}$} \\
\hline & & & DX & L & ML & $\mathrm{MN}$ & \\
\hline+ & - & + & $\mathrm{AG}$ & $\mathrm{AC}$ & AG & AG & E. coli \\
\hline
\end{tabular}

Legends : $\mathrm{DX}=$ Dextrose, $\mathrm{L}=$ Lactose, $\mathrm{ML}=$ Maltose, $\mathrm{MN}=$ Mannitol, $\mathrm{AG}=$ Acid and gas,$+=$ Positive, $-=$ Negative

\section{Pathological study}

\section{Gross lesions}

Post-mortem findings revealed cloudy and thickened air sacs (air sacculitis), congested and thickened liver capsule (Fig. 3) and congested and consolidated lung (Fig. 4) in some chickens. The pericardium was thickened and the spleen enlarged with severe congestion. All these lesions indicated the septicaemic form of colibacillosis. The duodenum showed mucus, congestion and haemorrhage (enteritis) and there was haemorrhage in the caecal tonsil. E. coli can cause several disease conditions (Barens and Gross, 1997; Chauhan and Roy, 1996). In the present study not all conditions induced by $E$. coli were recorded.

\section{Microscopic lesions}

The livers showed coagulation type of focal necrosis, infiltration of heterophils, lymphocytes, and macrophages mainly in portal area (Fig. 5). Spleen showed 
scattered pyknosis of lymphocytes and RE cell proliferation. Pericarditis was characterized by thickening of pericardium due to infiltration of RE cells. The lungs showed severe congestion, infiltration of heterophils, macrophages and lymphocytes in the wall of the bronchus as well as in the peribronchial alveoli (Fig. 6). In duodenum, there was severe infiltration of leukocytes, mainly heterophils, lymphocytes and macrophages in the submucosa. The colibacillosis in the present study could be categorized as entero-invasive. Similar lesions have been reported by Ghosh et al. (2006); Islam et al. (2003); Talha et al. (2001); Gagandeep et al. (2004); Zhou et al. (2002).

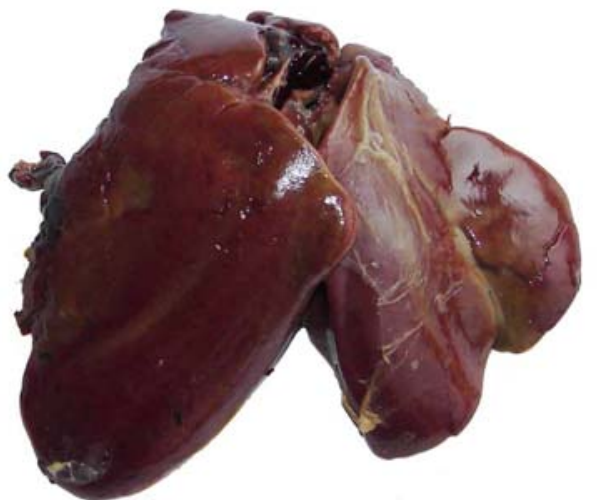

Fig. 3. Liver of E. coli infected chickens showing thickened capsule.

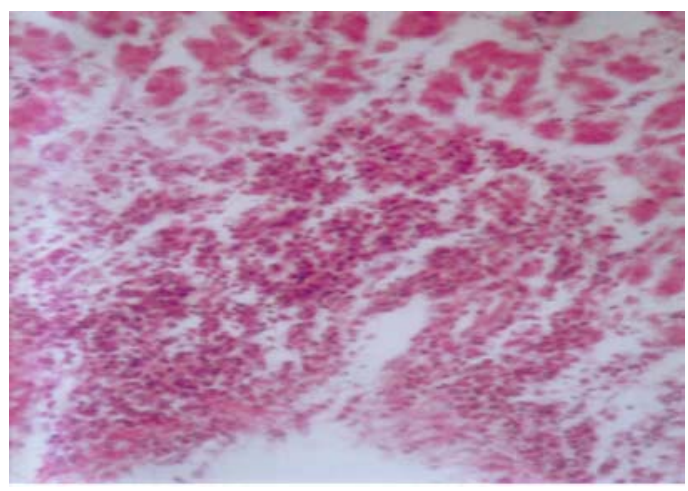

Fig. 5. Section of liver with E. coli infection showing infiltration of heterophils, lymphocytes and macrophages mainly in portal area ( H\& E , x 330)

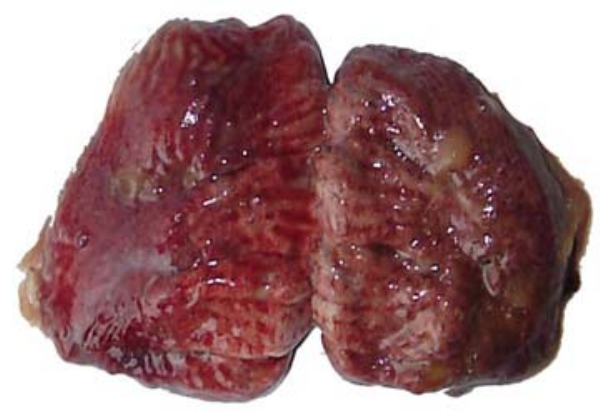

Fig. 4. Lungs of E. coli infected chickens showing congestion and consolidation

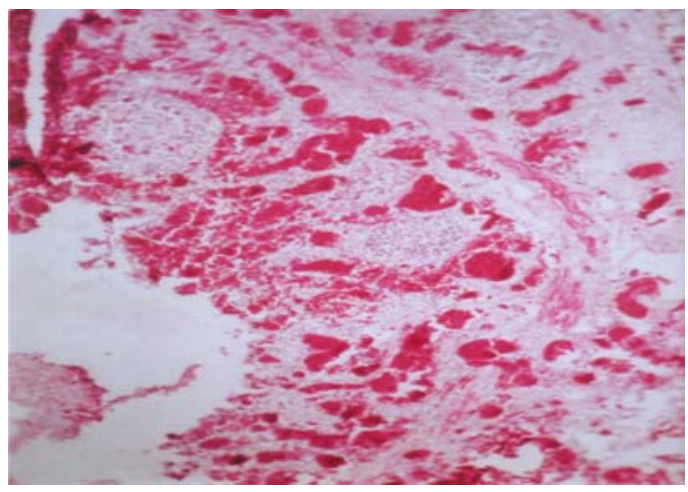

Fig. 6. Section of lung with E. coli infection showing severe congestion and infiltration of heterophils, macrophages and lymphocytes in the bronchial wall and peribrochial alveoli (H\&E, x 830)

The present study was conducted to determine prevalence of E. coli in apparently healthy and dead chickens and the pathological lesions in dead birds. The prevalence of E. coli in apparently healthy chickens was $83 \%$ and in dead chickens 
87\%. Further investigation should be focused on typing of E. coli and antibiotic sensitivity test.

\section{References}

Alam J 1995: Livestock resources in Bangladesh: Present status and future potentials. The University Press Limited, Dhaka, Bangladesh pp. 1-39.

Ali MY, Rahman MT, Islam MA, Choudhury KA, Rahman MA 1998: Characteristics of $E$. coli isolates of human and animal origin. Progressive Agriculture 9 221-224.

Barens JH, Gross WB 1997: Colibacillosis. In: Diseases of Poultry, edn : Calnec, BW 10 edn. Iowa University Press Ames, Iowa, USA pp. 131-141.

BBS (Bangladesh Bureau of Statistics) 1987: Bangladesh Bureau of statistics. The Bangladesh Census of Agriculture and Livestock, Dhaka 1983-1984.

Biswas PK, Uddin GMN, Barua H, Roy K, Biswas D, Ahad A, Debnath NC 2006: Causes of loss of Sonali chickens on smallholder households in Bangladesh. Preventive Veterinary Medicine 76 185-195.

Buxton A, Fraser G 1977: Animal Microbiology. Vol.1. Escherichia coli, Blackwell Scientific Publications, Oxford, London, Edinburgh, Melbourne, Australia pp. 92- 102

Carter G R 1986: Essentials of Veterinary Bacteriology and Mycology. $3^{\text {rd }}$ edn. Academic Press Inc, Harcourt Brace, Jovanovich, Toronto, Canada pp. 312-330.

Chauhan HVS, Roy S 1996: Poultry Diseases, Diagnosis and Treatment. $2^{\text {nd }}$ edn. International (P) Limited, Publishers. Bangalore, India, pp. 30-36

Derakhshantar A, Ghanbarpour R 2002: A study on avian cellulitis in broiler chickens. Veterivarski Archiv 72 277-284.

El-Sukhon SN, Musa A, Al-Attar M 2002: Studies on the bacterial etiology of air sacculitis of broilers in northern and middle Jordan with special reference to Escherichia coli, Ornithobacterium rhinotracheale and Bordetella avium. Avian Diseases 46 605-612.

Freeman BA 1985: Burrow's Text Book of Microbiology. 22 nd edn. In: WB Saunders Company, Philadelphia, London, Toronto, Mexico city, Rio de Janeiro, Sydney, Tokyo, pp. 464-475.

Gagandeep S, Sharma NS, Brar RS 2004: Mortality associated with bacterial infections in broilers at selected farms in Punjab. Journal of Research, Punjab Agricultural University 41 387-391.

Ghosh R.C, Hirpurkar SD, Suryawnshi PR 2006: Concurrent colibacillosis and infections bursal disease in broiler chicks. Indian Veterinary Journal 83 1019-1020.

Haider MG, Hossain MG, Chowdhury EH, Hossain MS, Das PM, Hossain MM 2003: Prevalence of enteric bacterial diseases in poultry of some selected poultry rearing units of SLDS-2 area: Isolation, identification and pathology of the identified diseases. Progressive Agriculture 14 51-79.

Hossain M.K, Ahmed M, Kabir H, Sarker MRR, Jalil MA, Adhikary GN 2004: Poultry diseases at Rajshahi in Bangladesh. Journal of Animal and Veterinary Advances 3 657-659. 
Islam MR, Das BC, Hossain KH, Lucky NS, Mostafa MG 2003: A study on the occurrence of poultry disease in Sylhet Region of Bangladesh. International Journal of Poultry Science 2 354-356.

Luna LG 1968: Manual of Histologic Staining Methods of the Armed Forces Institute of Pathology. $3^{\text {rd }}$ edn. McGraw Hill Book Co. New York, USA.

Mishra A, Sharda R, Chhabra D, Moghe MN 2002: E. coli isolated from domestic poultry farm. Indian Journal of Animal Science 72 727-729.

Pelczar JR, Michel J, Krieg NR, Chan ESS 1986: Microbiology. $5^{\text {th }}$ edn. McGraw-Hill Book Co, Inc, New York, USA, pp: 272.

Rahman M 2003a: Growth of poultry industry in Bangladesh: Poverty alleviation and employment. In: Procedings of $3^{\text {rd }}$ International Poultry Show and Seminar, from February 28 to March 2, 2003, held in Bangladesh China Frirndship Conference Center (BCFCC) Sher-e Bangla Nagar, Dhaka Bangladesh pp: 1-7.

Rahman MA 2003b: Diseases profile with pathogenicity and drug sensitivity of salmonellosis, colibacillosis and pasteurellosis in commercial chickens. MS Thesis. Department of Medicine, Bangladesh Agricultural University, Mymensingh pp. 71.

Rahman MA, Samad MA, Rahman MB, Kabir SMI 2004: Bacterio pathological studies on salmonellosis, colibacillosis and pasteurellosis in natural and experimental infections in chickens. Bangladesh Journal of Veterinary Medicine 2 1-8.

Roy P, Purushothaman V, Koteeswaran A, Dhillon AS 2006: Isolation, characterization and antimicrobial drug resistance pattern of Escherichia coli isolated from Japanese quail and their environment. Journal of Applied Poultry Research 15 442-446.

Sharada R, Krishnappa G, Raghavan R, Sreevinas G, Upandra HA 1999: Isolation and serotyping of E. coil from different pathological conditions in poultry. Indian Journal of Poultry Science 34 366-369.

Stubbs EL 1954: Necropsy procedures for chickens and other birds. In: Veterinary Necropsy Procedures. Jones TC. Lippincott Company, Philadelphia, USA. pp. 63-64.

Talha AFSM, Hossain MM, Chowdhury EH, Bari ASM, Islam MR, Das PM 2001: Poultry diseases occurring in Mymensingh district of Bangladesh. Bangladesh Veterinary Journal 18 20-23.

Thomas CGA 1988: Gram-negative Bacilli. In: Medical Microbiology, $6^{\text {th }}$ edn. Bailliere Tindall, UK pp: 273-74.

Zhou Z, Chen K, Li-YuBing YJ, Xiang SY, Yu-Fengzhi 2002: Observation of pathological changes of experimental colibacillosis in the chicks. Journal of Hunan Agricultural University 28 230-231. 